\title{
Anomalously large seismic amplifications in the seafloor area off the Kii peninsula
}

\author{
Takeshi Nakamura $\cdot$ Masaru Nakano $\cdot$ Naoki Hayashimoto $\cdot$ Narumi Takahashi \\ Hiroshi Takenaka $\cdot$ Taro Okamoto $\cdot$ Eiichiro Araki $\cdot$ Yoshiyuki Kaneda
}

Received: 31 May 2013/Accepted: 2 January 2014/Published online: 14 January 2014

(C) The Author(s) 2014. This article is published with open access at Springerlink.com

\begin{abstract}
Seismic wave amplifications were investigated using strong-motion data obtained from the ground's surface (K-net) on the Kii peninsula (southwestern Japan) and from the network of twenty seismic stations on the seafloor (DONET) located off the peninsula near the Nankai trough. Observed seismograms show that seismic signals at DONET stations are significantly larger than those at K-net stations, independent of epicentral distances. In order to investigate the cause of such amplifications, seismic wavefields for local events were simulated using the finitedifference method, in which a realistic 3D velocity structure in and around the peninsula was incorporated. Our simulation results demonstrate that seismic waves are significantly amplified at DONET stations in relation to the presence of underlying low-velocity sediment layers with a total thickness of up to $10 \mathrm{~km}$. Our simulations also show considerable variations in the degree of amplification
\end{abstract}

\footnotetext{
T. Nakamura $(\bowtie) \cdot$ M. Nakano · N. Takahashi $\cdot$ Y. Kaneda Earthquake and Tsunami Research Project for Disaster Prevention, Japan Agency for Marine-Earth Science and Technology, 3173-25 Showa-machi, Kanazawa-ku, Yokohama 236-0001, Japan

e-mail: t_nakamura@jamstec.go.jp

M. Nakano

e-mail: mnakano@jamstec.go.jp

N. Takahashi

e-mail: narumi@jamstec.go.jp

Y. Kaneda

e-mail: kaneday@jamstec.go.jp

N. Hayashimoto

Seismology and Volcanology Research Department,

Meteorological Research Institute, Nagamine 1-1,

Tsukuba 305-0052, Japan

e-mail: hayashim@mri-jma.go.jp
}

among DONET stations, which is attributed to differences in the thickness of the sediment layers. The degree of amplification is relatively low at stations above thin sediment layers near the trough axis, but seismic signals are much more amplified at stations closer to the Kii peninsula, where sediment layers are thicker than those at the trough axis. Simulation results are consistent with observations. This study, based on seafloor observations and simulations, indicates that because seismic signals are amplified due to the ocean-specific structures, the magnitude of earthquakes would be overestimated if procedures applied to data observed at land stations are used without corrections.

Keywords DONET $\cdot$ Earthquake early warning $\cdot$ Seismic wave propagation $\cdot$ Finite-difference method $\cdot$ Seafloor observation - Tonankai area

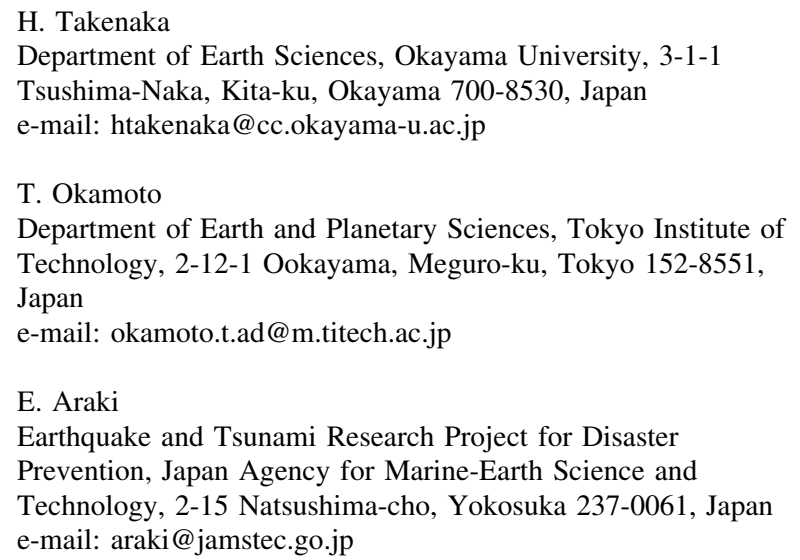




\section{Introduction}

Over the past decade, permanent observation networks for earthquakes and tsunamis have been developed on the seafloor by maritime nations. Seismic and tsunami data observed at these networks now have significantly improved station coverage, particularly over coastal and ocean areas. Seafloor observations in real-time systems provide a way of detecting much earlier signals from suboceanic events, which enhances the effectiveness of earthquake early warnings (EEW) for disaster mitigation and prevention. For example, in northeastern Japan, strong ground motions measuring more than $700 \mathrm{~cm} / \mathrm{s} / \mathrm{s}$ were observed by the Kushiro geophysical observatory system (Watanabe et al. 2006), which is deployed on the seafloor very close to the rupture area of the 2003 Tokachi-oki earthquake (M8.0). During the 2003 Tokachi-oki earthquake, the Kushiro system observed geodetic deformations and tsunamis using pressure gauges (e.g., Mikada et al. 2006), the data from which greatly contributed to constraining the fault size and improving the resolution when making analyses of the slip distributions on the fault plane in offshore areas (Baba et al. 2006; Romano et al. 2010). In another seafloor observatory system at Muroto (southwestern Japan), pressure gauges recorded tsunamis $20 \mathrm{~min}$ earlier than the arrival at coastal areas (Matsumoto and Mikada 2005), during the 2004 off the Kii peninsula earthquake (M7.4), which occurred near the trough axis.

Recently, the Japan Agency for Marine-Earth Science and Technology (JAMSTEC) developed a seafloor observation network consisting of twenty seismic and tsunami stations near the Nankai trough, off the Kii peninsula in southwestern Japan (Kawaguchi et al. 2011), known as the Dense Oceanfloor Network System for Earthquakes and Tsunamis (DONET). Observations at the first station began in March 2010, and all 20 stations were installed by August 2011.

DONET data are intended for use in issuing EEWs in the near future. The EEW system in Japan is operated by the Japan Meteorological Agency (JMA), and uses a combination of several techniques and data for the estimation of earthquake location, magnitude, and ground motions at target sites (e.g., Hoshiba et al. 2008; Kamigaichi et al. 2009). In the EEW system, the magnitude and source location of an earthquake are estimated using realtime acceleration waveforms from stations near the source. The system then forecasts the seismic intensity and the arrival time at each area using source parameters and the attenuation relation of seismic amplitudes. Finally, early warnings are then issued to areas where large seismic intensities are expected. During real-time analyses, it is extremely important to gain an accurate measurement of the earthquake magnitude, which is calculated from the maximum amplitude of seismograms, since the seismic intensity estimated from the magnitude determines whether warnings are issued or not. This is also true for other realtime analyses using acceleration data such as the seismic alert system (SAS) in Mexico (Espinosa-Aranda et al. 1995; Iglesias et al. 2007), and the EEW systems in Taiwan (Wu and Teng, 2002).

DONET stations are installed off the Kii peninsula on the seafloor, in water depths of between $1,900 \mathrm{~m}$ and 4,400 m. In this area, Nakanishi et al. (2002) presented a very low $P$-wave velocity $(V \mathrm{p})$ of less than $2.0 \mathrm{~km} / \mathrm{s}$ in the shallow sediment layers, using results from a wideangle seismic survey. Since seismic waves propagating through low-velocity layers are generally amplified, it is likely that seismic motions observed at DONET stations may be amplified compared to observations made at bedrock sites. Evaluating such amplitudes at DONET stations without correcting such amplifications would thus result in an overestimation of the magnitude of events and lead to issuing false EEW. In order to deliver precise EEWs, it is therefore necessary to quantitatively investigate the degree of seismic wave amplification and to then discuss whether we can apply the rapid analysis procedure, which is currently constructed from analyses of land seismic data, to data obtained from seafloor observations such as DONET.

In this study, we therefore investigate the amplification of seismic waves at land and DONET seismic stations, based on observed data and seismic wave simulations. Recent studies on the applicability of seafloor observation data for EEW show that displacement amplitudes at DONET stations tend to be larger than those at land stations, which results in larger magnitude estimations than catalogue values by an approximate difference of 0.6 between DONET and land stations (Hayashimoto and Hoshiba, 2012, unpublished results). Other studies such as that of Hayashimoto and Hoshiba (2013) used data at JMA Tonankai seafloor stations (located on the east side of DONET stations) and have also shown similar results using large seismic amplifications. Hayashimoto and Hoshiba (2013) pointed out that effects related to the site, such as the seafloor structure and complex structures such as sediment layers, could be possible causes of the amplifications and their variations among stations.

This study demonstrates large amplifications of seismic waves and their significant spatial variations that occur in the seafloor area, based on both observation data and simulations for local events. The results obtained show that the presence of low-velocity sediment layers partially contributes to amplifying seismic waves. Results obtained from observation data and simulations are important in gaining an understanding of the cause of seismic wave amplifications at DONET stations and therefore help to 
reduce an overestimation of the magnitude in order to deliver an accurate EEW.

\section{Peak amplitudes observed at land and seafloor stations}

We investigated the distribution of peak amplitudes of acceleration, velocity, and displacement waveforms from strong motion data at K-net stations, located in and around the Kii peninsula, operated by National Research Institute for Earth Science and Disaster Prevention (NIED), and DONET stations, located off the Kii peninsula, operated by
JAMSTEC. K-net and DONET stations are installed at the ground's surface on land and at the seafloor, respectively. 18 of the DONET stations were buried by penetrating a seismometer package into the seafloor in order to reduce noise contamination due to bottom currents and thermal changes in observations (Araki et al. 2013). Two of the stations are not buried because of stiff soil conditions, and these are not used in the following analysis.

We analyzed four moderate-size crustal events occurring beneath the Kii peninsula between January 2011 and December 2012. These events had magnitudes larger than 4.0 , source depths of less than $30 \mathrm{~km}$, and epicentral

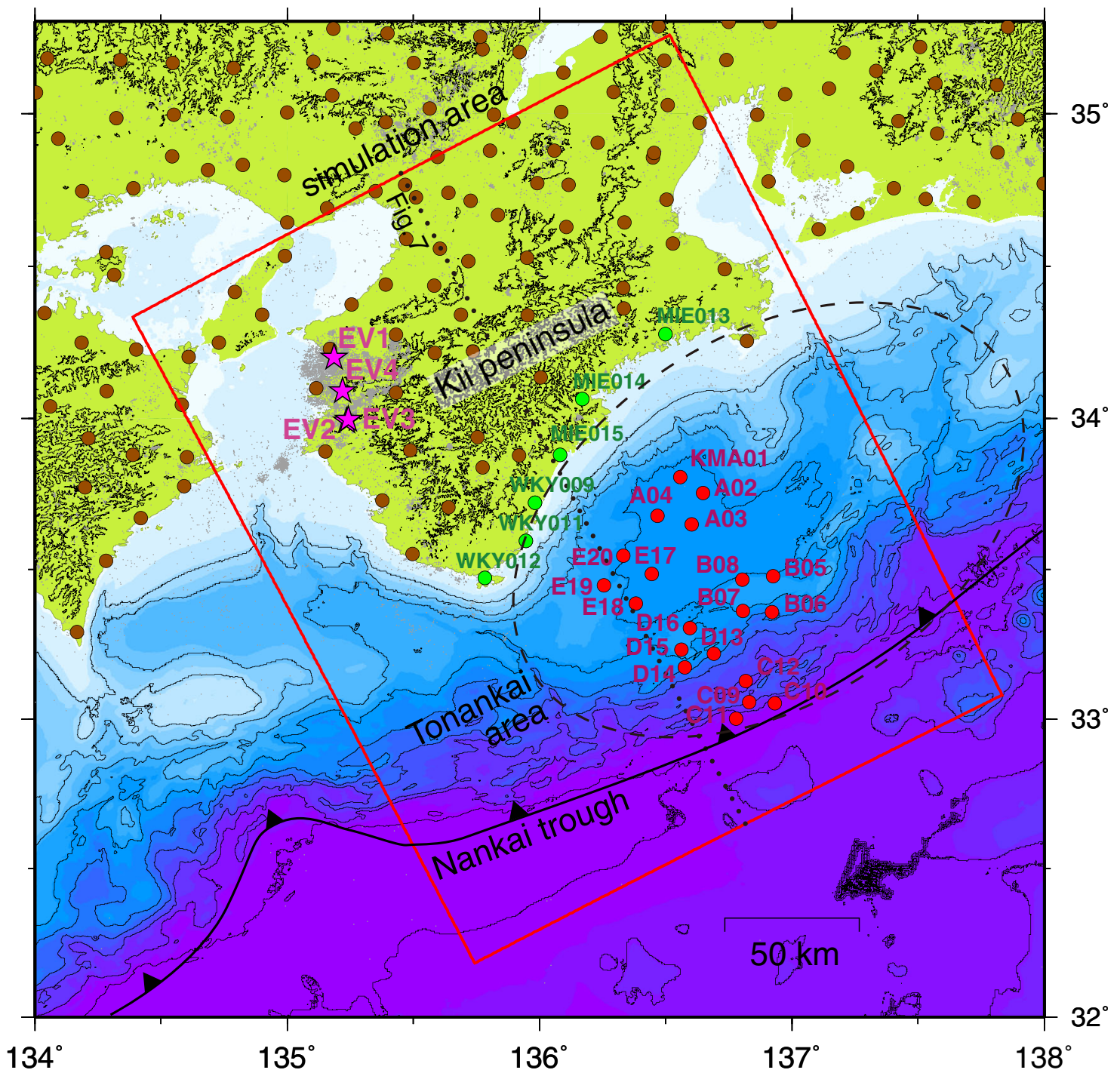

Fig. 1 Epicentral location of events (purple stars) analyzed in this study. Brown and red circles indicate the location of K-net and DONET stations, respectively. Green circles indicate K-net stations located at coastal areas near DONET stations. Gray dots indicate the epicenter distribution of background seismicity from January 2011 to December 2012. Black contour lines indicate land and seafloor

topography at intervals of $500 \mathrm{~m}$. Red rectangle indicates the area simulated using the finite-difference method. The area enclosed by a dashed line, the Tonankai area, is the anticipated source area of an M8-class large event. Dot line indicates the location of cross sections shown in Fig. 7 for the structure model used in our simulation and the snapshots 
Table 1 List of events analyzed in the study

\begin{tabular}{llllll}
\hline Event no. & $\begin{array}{l}\text { Origin time } \\
\text { (UTC yyyy/mm/dd hh:mm:ss) }\end{array}$ & $M_{\mathrm{JMA}}{ }^{\mathrm{a}}\left(M_{\mathrm{w}}{ }^{\mathrm{b}}\right)$ & $\begin{array}{l}\text { Longitude }^{\mathrm{a}} \\
(\text { degree })\end{array}$ & $\begin{array}{l}\text { Latitude }^{\mathrm{a}} \\
(\text { degree })\end{array}$ & $\begin{array}{l}\text { Depth }^{\mathrm{a}}\left(\text { Depth }^{\mathrm{b}}\right) \\
(\mathrm{km})\end{array}$ \\
\hline 1 & $2011 / 05 / 1014: 01: 53.40$ & $4.2(4.0)$ & 135.1858 & 34.1995 & $5.11(5.00)$ \\
2 & $2011 / 07 / 0510: 18: 43.44$ & $5.5(5.0)$ & 135.2342 & 33.9905 & $7.33(8.00)$ \\
3 & $2011 / 07 / 0510: 34: 55.64$ & $4.5(4.3)$ & 135.2423 & 33.9965 & $7.08(8.00)$ \\
4 & $2011 / 07 / 3001: 07: 04.74$ & $4.0(3.8)$ & 135.2183 & 34.0895 & $6.55(8.00)$ \\
\hline
\end{tabular}

a JMA hypocenter catalogue

b NIED moment tensor determination results

distances of less than $200 \mathrm{~km}$ at DONET stations. Locations of stations and the events are shown in Fig. 1; source parameters are listed in Table 1; and an example of the observed waveforms at K-net and DONET stations is shown in Fig. 2.

We applied a high-pass filter with a corner frequency $0.1 \mathrm{~Hz}$ to the acceleration data to suppress noise due to inherent sensor hysteresis, which is commonly observed in strong-motion sensors, and also due to low coupling with the ground site. We then applied a band-pass filter using the frequency range $0.1-10 \mathrm{~Hz}$ to analyze seismic signals. Peak ground acceleration (PGA) was measured from the larger amplitude of two horizontal components following the procedure used for constructing empirical equations for PGA by Si and Midorikawa (1999). Peak ground velocity (PGV) was then obtained by integrating the acceleration data and measuring larger values of the horizontal components following that for PGV by $\mathrm{Si}$ and Midorikawa (1999). Peak ground displacement (PGD) was obtained after integrating the velocity data and measuring peak amplitude in the waveforms of vector sums of the horizontal components following the definition of empirical equations for earthquake magnitudes by Tsuboi (1954).

The measured PGA, PGV, and PGD are subsequently plotted as a function of distance from the source in Fig. 3a. Low-quality data such as those showing baseline drifts or low signal to noise ratio after numerical integration were removed, as these may have been caused by noise in the lowfrequency components, which cannot be suppressed using a filter application. As some of the DONET stations did not start operating until August 2011, values for events that occurred before these stations were installed are not plotted for these stations. Figure $3 \mathrm{a}$ also shows the empirical attenuation curves superimposed for PGA and PGV ( $\mathrm{Si}$ and Midorikawa 1999), and PGD (Tsuboi 1954). Moment magnitudes $(M \mathrm{w})$ were used to obtain the attenuation curves of PGA and PGV following Si and Midorikawa (1999) and the JMA magnitudes $\left(M_{\mathrm{JMA}}\right)$ for PGD following Tsuboi (1954). Note that the equation of PGV by Si and Midorikawa (1999) is defined not on the ground's surface but on stiff soil with $V \mathrm{~s}=600 \mathrm{~m} / \mathrm{s}$. In contrast, the PGV in our plots were measured on the ground's surface or on the seafloor, and were not corrected for site amplifications near the surface, since the site effect amplification factors (such as average $S$ wave velocity from ground surface to a depth of $30 \mathrm{~m}$ (AVS30)) are unavailable in ocean areas.

The overall trends of attenuations for the observed PGA, PGV, and PGD can be seen to almost follow the empirical attenuation curves, both at K-net and DONET stations. It is considered that the systematic offsets between observations and equations for Events 1 and 4 may be due to limitations in applying empirical equations to these moderate-size events, and/or errors in estimations of magnitudes. In Fig. 3a, it is possible to observe that the distribution of PGA, PGV, and PGD values can be separated into two groups: those at K-net and those at DONET stations. It is clear that the measured PGD at DONET stations are systematically larger than those at K-net stations compared at the same distances, and also larger than the values expected from the empirical equation, implying that low frequency components of seismic waves are largely amplified at DONET stations.

In order to emphasize this observation, PGD values measured from low frequency components of $0.1-0.2 \mathrm{~Hz}$ are plotted in Fig. 3b. Note that this frequency band is the same as that used in the following section, "Seismic wave simulations for local events", in which simulated waveforms are analyzed. Figure $3 b$ clearly indicates the existence of much larger amplifications at DONET stations compared with those at K-net. The PGD values at K-net stations are shown to be mostly smaller than the empirical relation because of the narrow band data. In order to investigate the cause of the amplifications at DONET stations, we simulated seismic wavefields in land and ocean areas, as described in the following section.

\section{Seismic wave simulations for local events}

We calculated seismic wavefields for the same local events analyzed and referred to in the above section, "Peak amplitudes observed at land and seafloor stations". We employed the heterogeneity, oceanic layer, and topography 


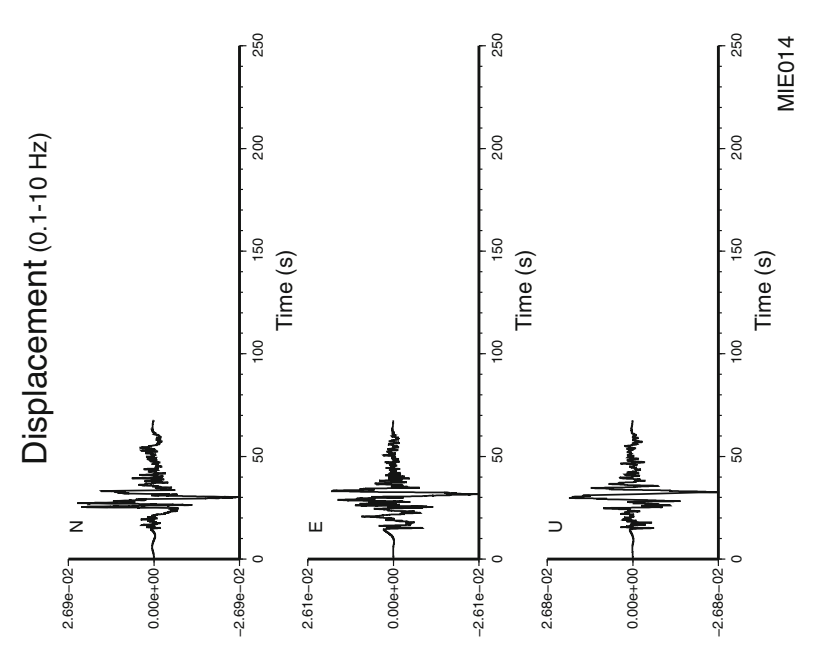

(uv) $\cdot d u r$

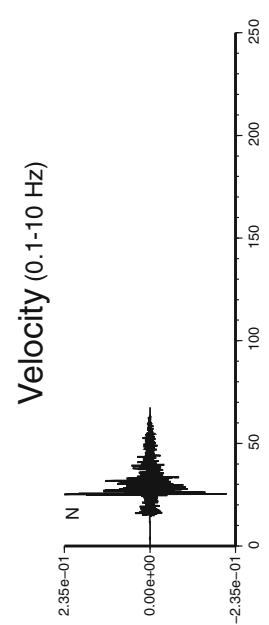

(s/uo) ·duv

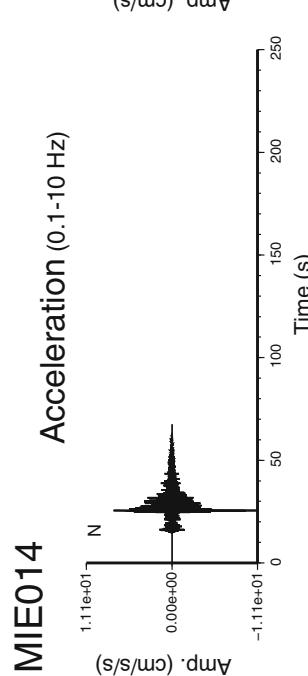

(uv) d dur

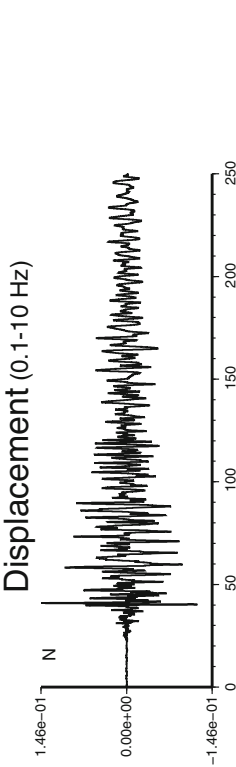

(uv) $d u r$

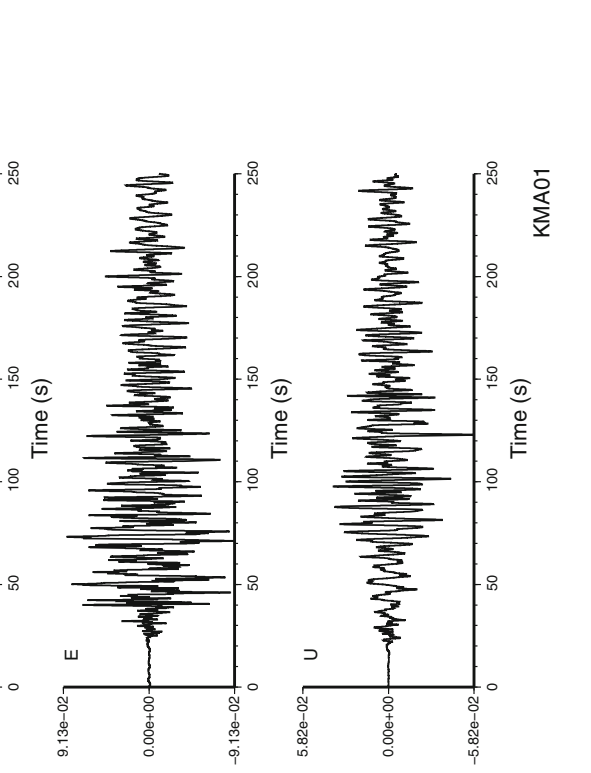

(uo) $\cdot d u r$

(u) $\cdot d u r \quad$ if

$\frac{3}{5}$

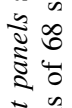

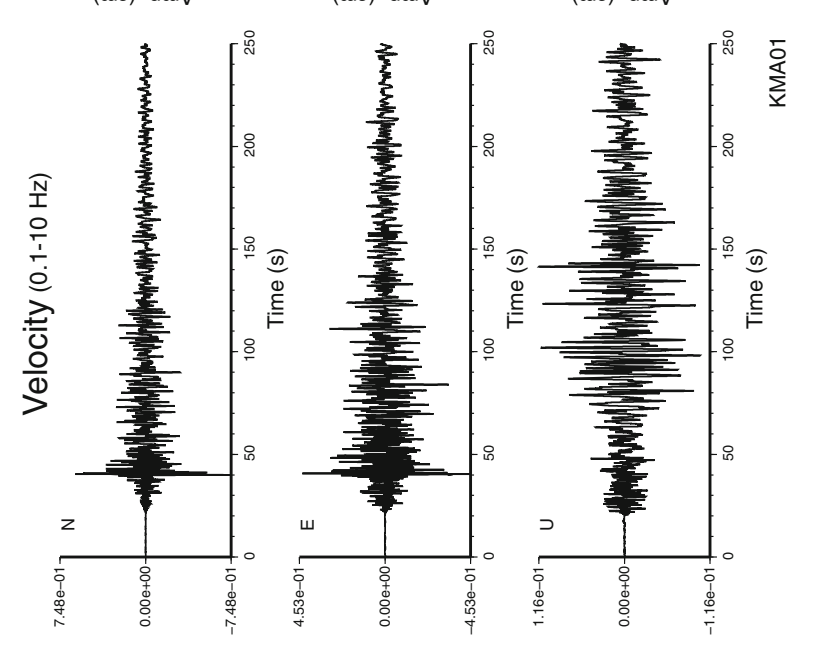

(s/uo) $d$ dur

(s/uo) d dur

(s/uo) $\cdot d u r$

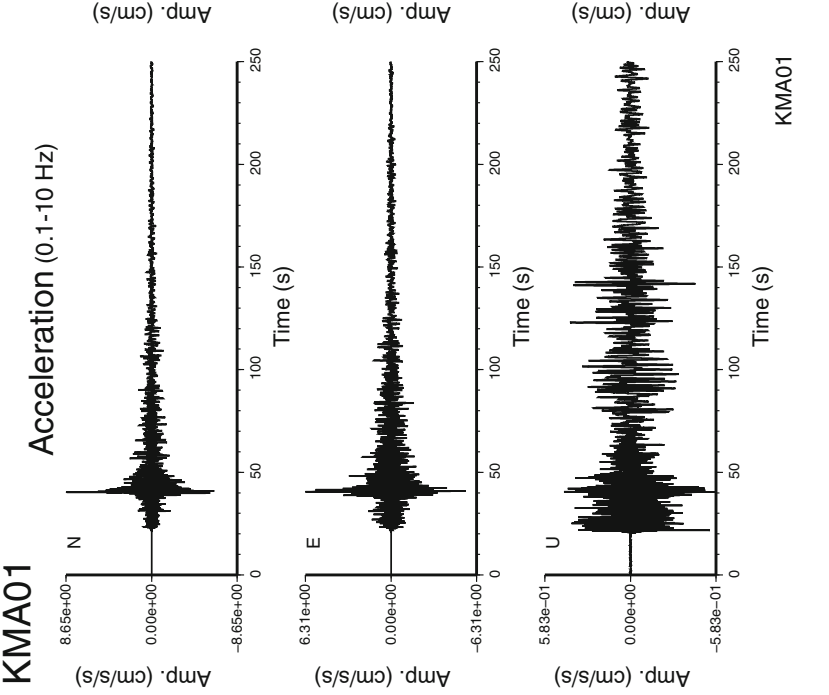

烦

ธี

记

車

$\because \frac{1}{0}$

$\approx \frac{1}{5}$

च

वे 퓰

흘

흉

凷边

ไัญ

ㅎ․

유리

$\sum$ है

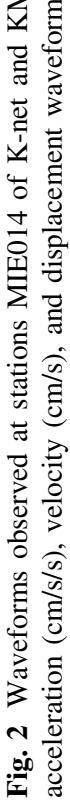


(a) Event 1

(2011/05/11 14:01,

MJMA 4.2, Mw 4.0, depth $5.0 \mathrm{~km}$ )

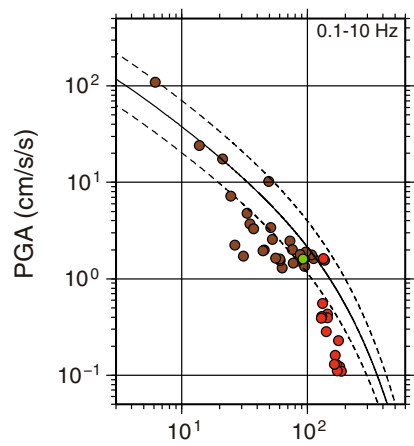

Hypocentral distance (km)

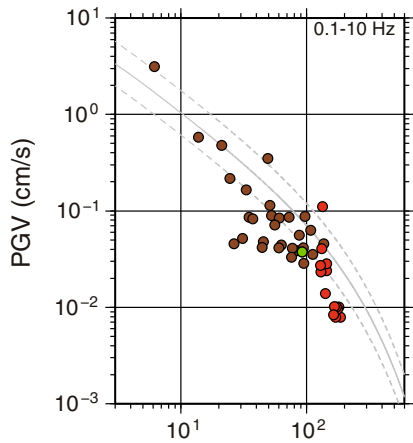

Hypocentral distance $(\mathrm{km})$

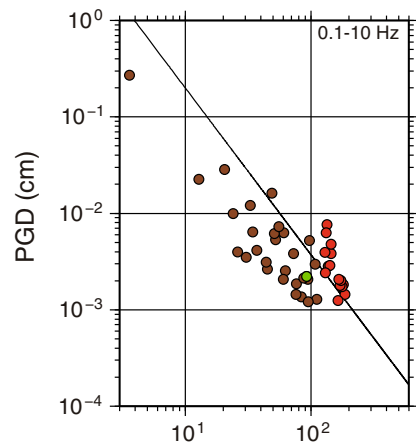

Epicentral distance (km)

(b)

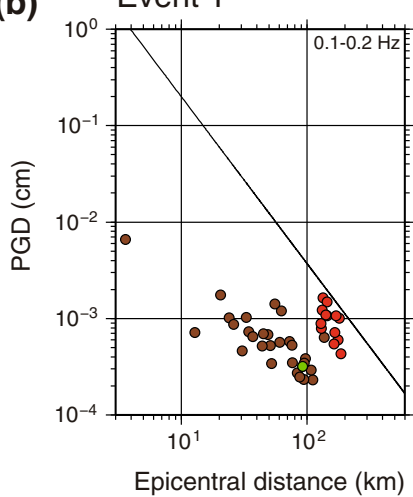

Event 2

(2011/07/05 10:18,

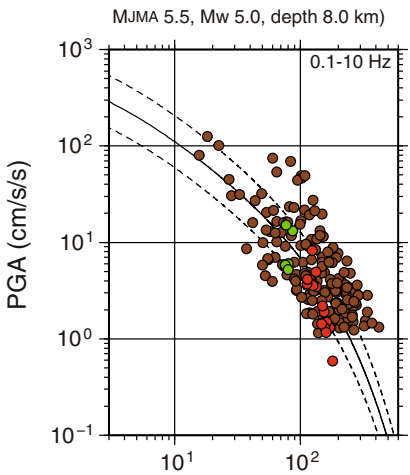

Hypocentral distance (km)

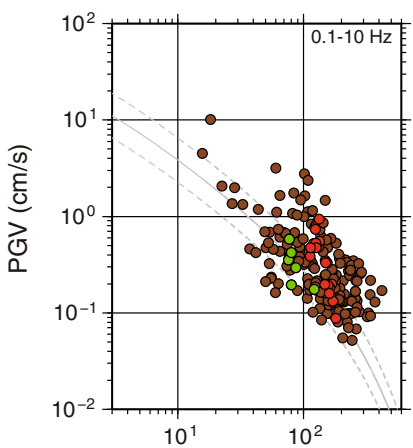

Hypocentral distance (km)

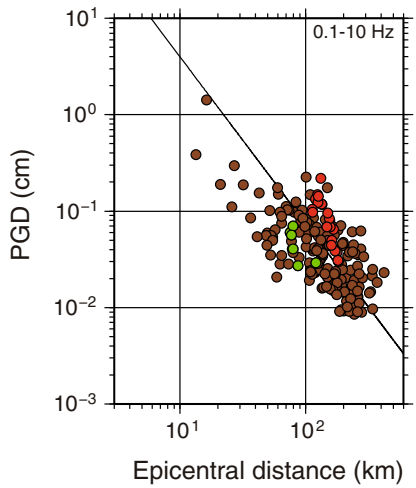

Event 2

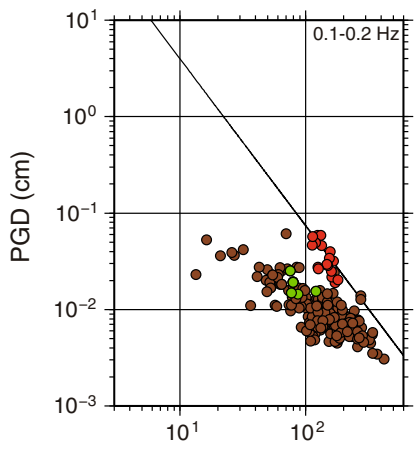

Epicentral distance $(\mathrm{km})$
Event 3

(2011/07/05 10:34,

MJMA 4.5, Mw 4.3, depth $8.0 \mathrm{~km}$ )

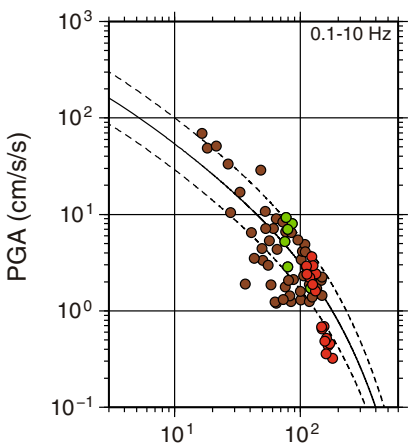

Hypocentral distance (km)

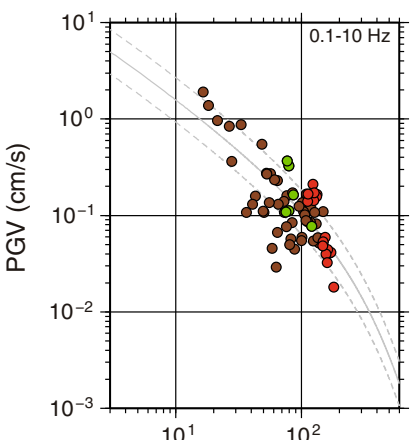

Hypocentral distance (km)

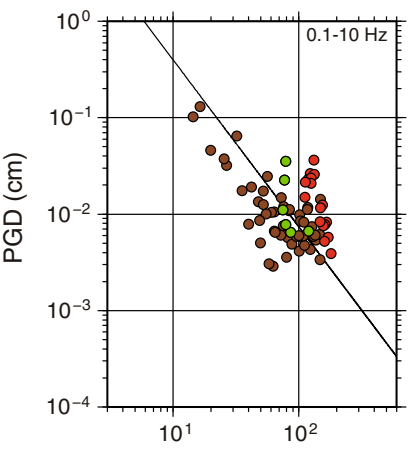

Epicentral distance (km)

Event 3

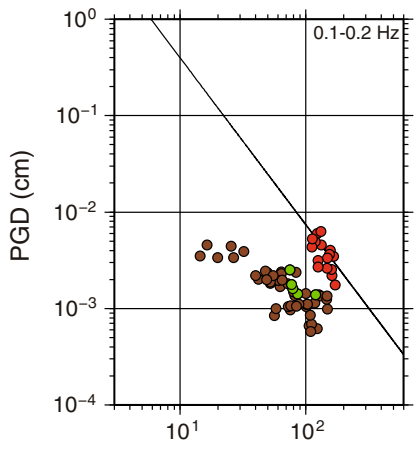

Epicentral distance (km)
Event 4

(2011/07/30 01:07,

MJMA 4.0, Mw 3.8, depth 8.0 km)

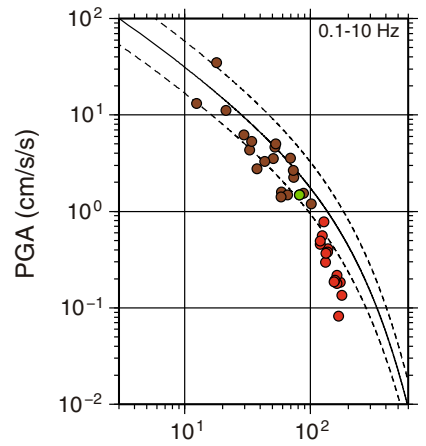

Hypocentral distance (km)

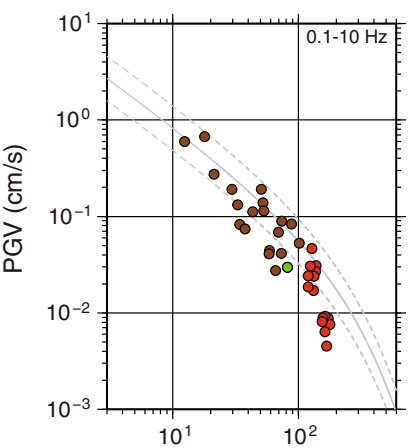

Hypocentral distance (km)

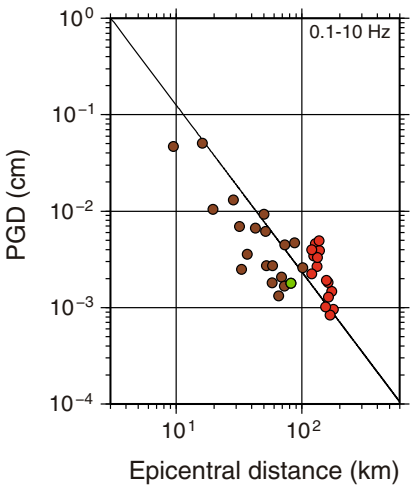

Event 4

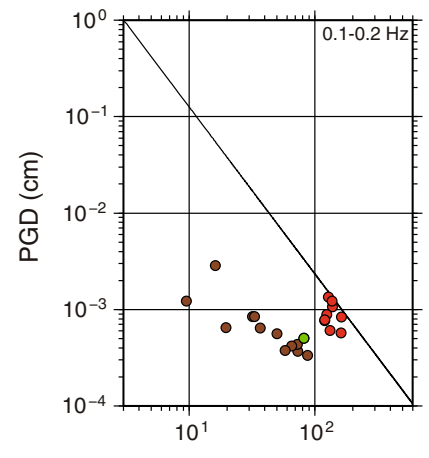

Epicentral distance (km) 
4Fig. 3 a Peak amplitudes of waveforms for each event measured in the frequency range $0.1-10 \mathrm{~Hz}$. Top, middle, and bottom panels show the peak ground acceleration (PGA), the peak velocity (PGV), and the peak displacement (PGD), respectively. PGA and PGV are plotted as a function of hypocentral distance, and PGD is plotted as a function of epicentral distance. Brown and red circles indicate K-net and DONET stations, respectively. Green circles indicate K-net stations located at coastal areas near DONET stations. Attenuation curves and their standard deviations based on empirical equations by $\mathrm{Si}$ and Midorikawa (1999) are indicated by solid and dashed lines, respectively, in the top (PGA) and middle panels (PGV). Attenuation curves, based on empirical equations of magnitudes by Tsuboi (1954), are indicated by the solid lines in the bottom panel (PGD). Note that the empirical relation of PGV (gray lines) is evaluated on stiff soil with $V \mathrm{~s}=600 \mathrm{~m} / \mathrm{s}$, while the observed values are obtained at the ground's surface or at the seafloor (see text for the details). b PGD for each event measured in the frequency range $0.1-0.2 \mathrm{~Hz}$

(HOT)-FDM scheme, presented by Nakamura et al. (2012) to calculate seismic wavefields in both the land and ocean areas. HOT-FDM implements three-dimensional fluidsolid boundary conditions correctly at the ground's surface (free-surface) and seafloor, giving it an advantage over conventional FDM schemes that do not implement the condition into the simulation. We thus considered the HOT-FDM scheme to be appropriate for use in the simulation of waveforms at stations on both the ground's surface and the seafloor.

We used a cosine-type pulse as a source-time function with the duration time based on scaling laws proportional to magnitude (e.g., Kikuchi 2003; Kanamori and Brodsky 2004), and used the F-net solution provided by NIED for the hypocenter and focal mechanism in our simulation. A sediment layer model from Japan Seismic Hazard Information Station (JSHIS) was used for the sediments, accretionary prism, and seismic basement, and is composed in total of 32 layers with $V \mathrm{~s}=0.35-3.30 \mathrm{~km} / \mathrm{s}$. In this study, we refer to the low velocity layers above the seismic basement simply as "sediment layers", and such layers have a total thickness between several and ten kilometers around the DONET stations. For the oceanic crust (oceanic layers 2 and 3) and oceanic mantle, a structure model of the Nankai Rendo Project 2011 model (Citak et al. 2012, unpublished results) was used, and the Japan Meteorological Agency (JMA) 2001 velocity model (Ueno et al. 2002) was employed for the structure of continental crust. Density in the crust and mantle is provided by an empirical relation as a function of $V p$ given by Brocher (2005). For land and ocean-bottom topographies, $50 \mathrm{~m}$ and $500 \mathrm{~m}$ mesh data were used, as provided by the Geospatial Information Authority of Japan (GSI) and the Japan Oceanographic Data Center (JODC), respectively. A seawater layer with $V p=1.5$, $V \mathrm{~s}=0.0 \mathrm{~km} / \mathrm{s}$, and $\rho=1.05 \mathrm{~g} / \mathrm{cm}^{3}$ was assumed, and an air layer with $V \mathrm{p}=V \mathrm{~s}=0.0 \mathrm{~km} / \mathrm{s}$ was implemented to incorporate the effect of land topography (Takenaka et al. 2009).

The computational domain in this study covers an area of $270 \times 220 \mathrm{~km}$ in and around the sources and stations as shown in Fig. 1, and extends to a depth of $94 \mathrm{~km}$. The spatial and temporal grid spacings are $0.2 \mathrm{~km}$ and $0.01 \mathrm{~s}$, respectively, and the time step is in total 25,000 steps, corresponding to $250.0 \mathrm{~s}$. Artificial reflections from the sides and bottom of the computational domain were avoided by implementation in our code of convolutional, perfectly matched layers (PMLs) (e.g., Drossaert and Giannopoulos, 2007).

For the largest event (Event 2 in Table 1), synthetic and observed waveforms from coastal stations of K-net (green circles in Fig. 1) and DONET stations are compared in Fig. 4. Waveforms were converted to radial, transverse, and vertical components using the sensor azimuth (Nakano et al. 2012) and the back azimuth estimated from the station location and the source epicenter. The synthetic waveforms represent particle velocity (unit: $\mathrm{cm} / \mathrm{s}$ ) that is band-pass filtered in the frequency range $0.1-0.2 \mathrm{~Hz}$. For the upper corner frequency of $0.2 \mathrm{~Hz}$ and grid spacing of $0.2 \mathrm{~km}$ used in our simulation, the model has more than eight grid points per minimum shear wavelength in solid media, indicating that we incorporated many more grid points than would be included under standard sampling conditions, using fourth-order differential equations in order to suppress the numerical dispersion (Alford et al. 1974; Moczo et al. 2000). The observed waveforms shown are also particle velocity, and are obtained from the integration of acceleration data which are filtered with the same frequency range as that used in the synthetic waveforms.

For K-net stations, the simulations reproduced the observations well in terms of arrival times and amplitudes of the main phases (i.e., those with the largest amplitudes) and waveforms as a whole. This demonstrates that the HOT-FDM scheme and subsurface structures used in our simulation are appropriate for the reproduction of observations at the stations. For DONET stations, synthetic waveforms are not as well reproduced as those at K-net stations for the one-by-one wave packet, and it is considered that it may be necessary in future studies to modify subsurface structures in the ocean area for the simulations. However, it is evident that the synthetic waveforms reproduce the features of observed waveforms, such as maximum amplitudes and long-lasting waveform coda, and we therefore considered that these synthetic waveforms could be used in our analyses, which would focus on the cause of seismic wave amplifications. In the subsequent sections, we use the simulation results from both K-net and DONET stations to discuss the amplifications.

\section{Comparison of peak amplitudes between observations and simulation results}

Observed and simulated PGV and PGD at K-net and DONET stations are compared in Fig. 5, and PGV and PGD are compared among DONET stations in Fig. 6. 

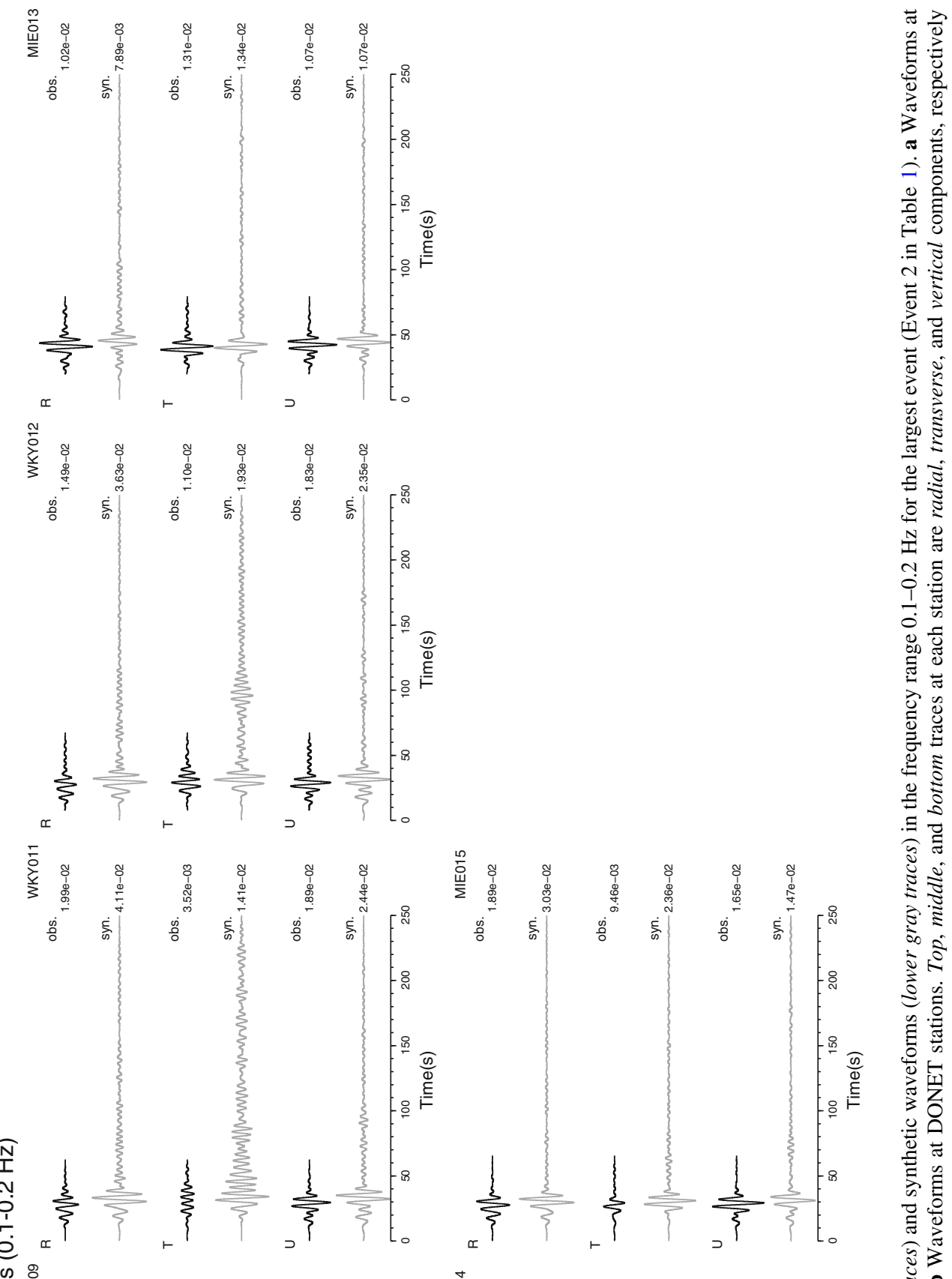

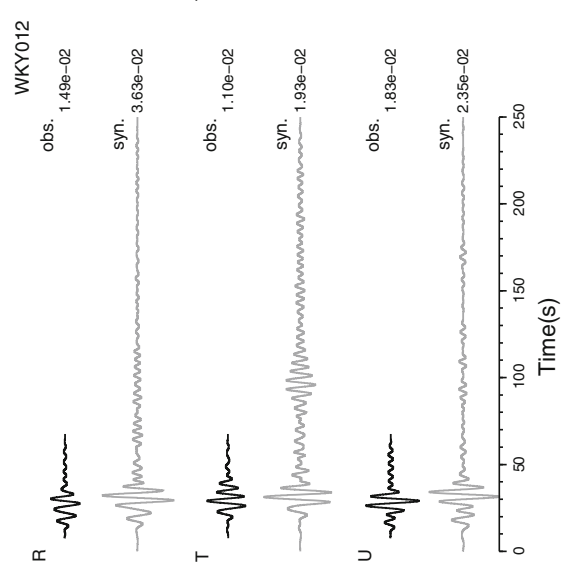

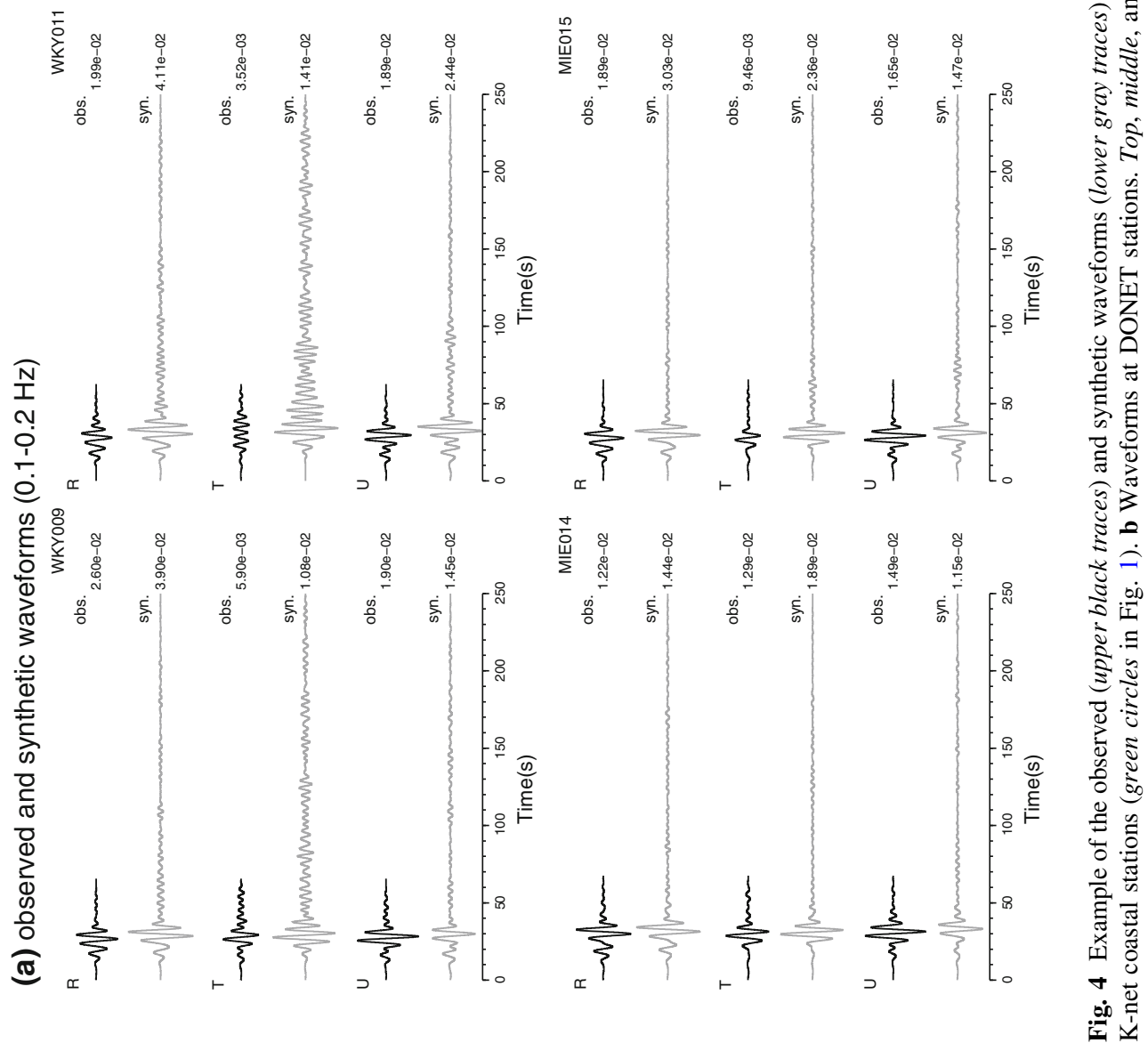



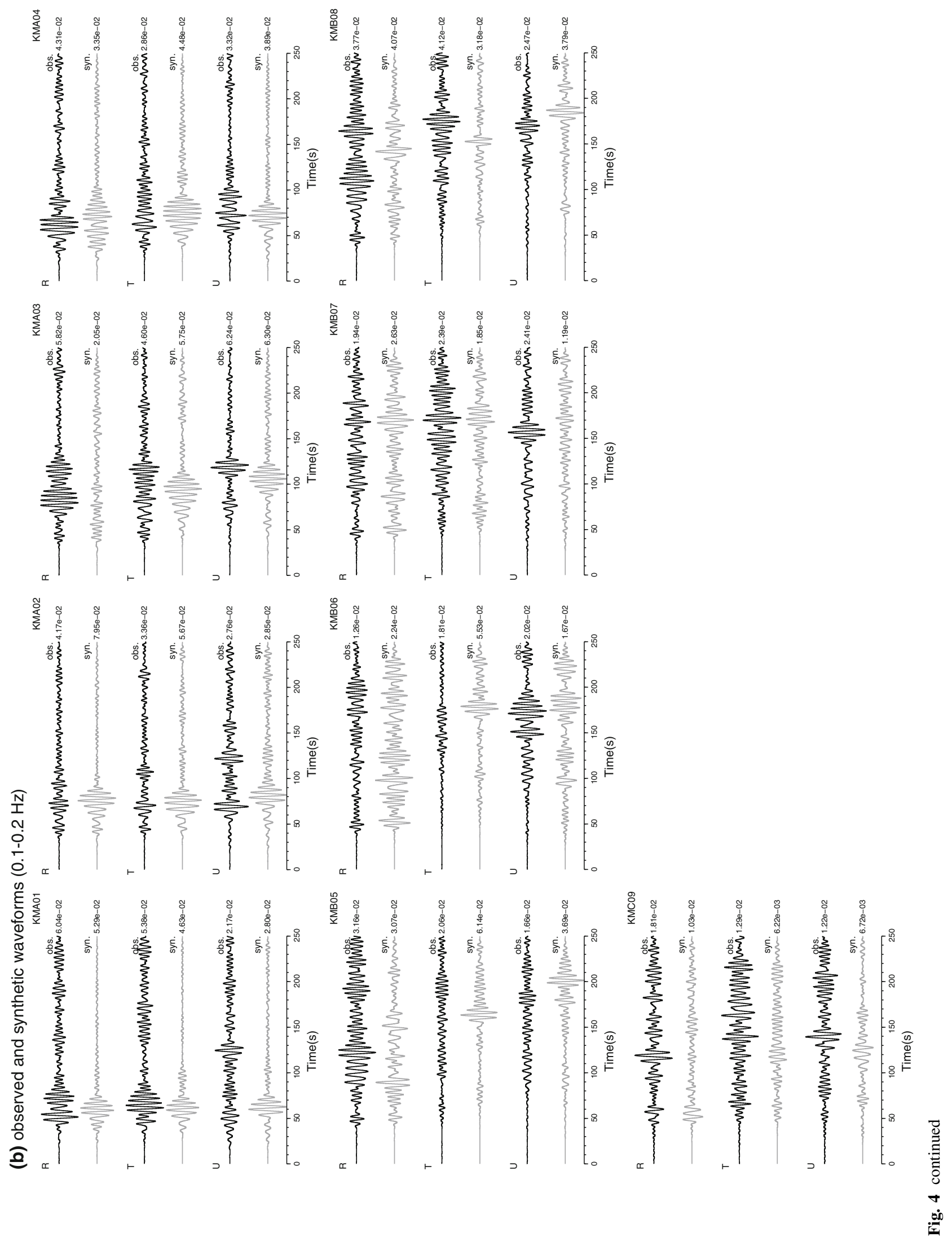

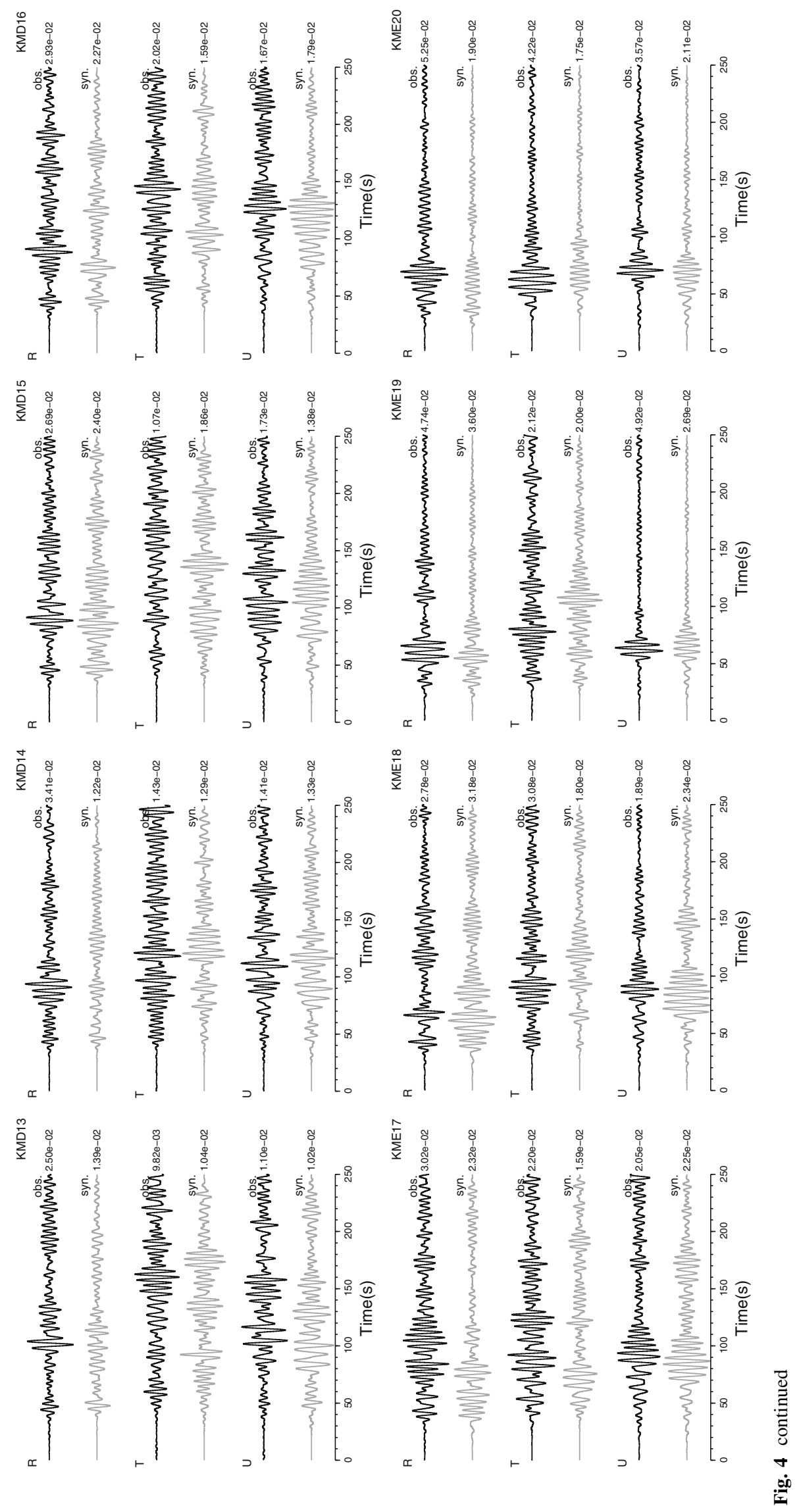


\section{Event 1}
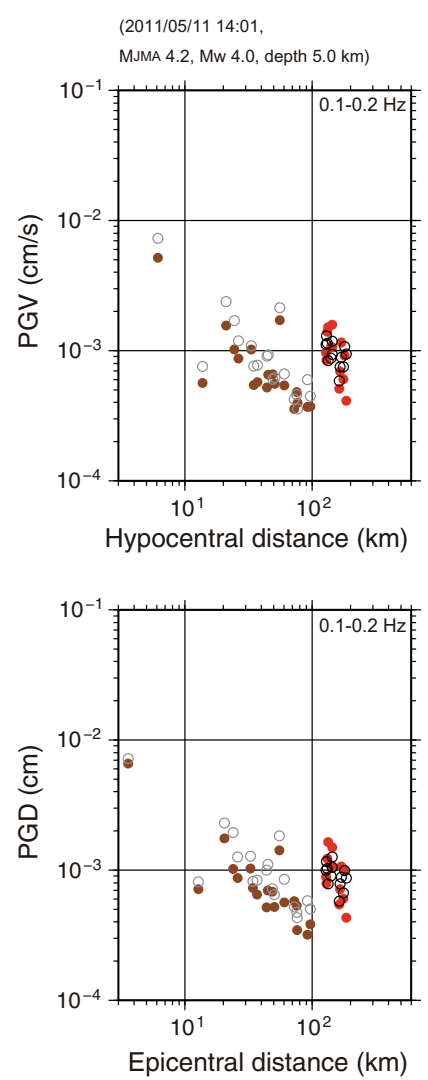

Event 2
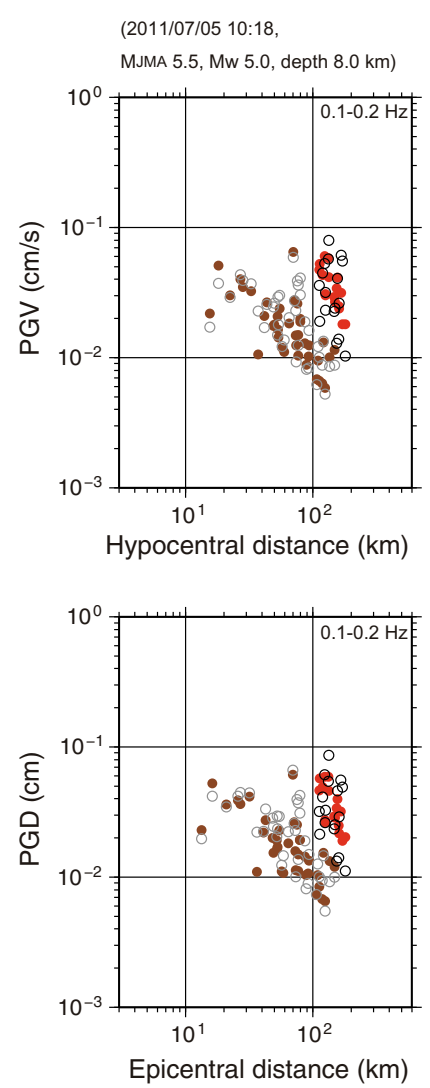

Fig. 5 Comparison of PGV and PGD for synthetic and observed waveforms in the frequency range $0.1-0.2 \mathrm{~Hz}$ at K-net and DONET stations. Solid brown and red circles indicate the amplitudes observed at K-net and DONET stations, respectively. Open gray and black circles indicate the amplitudes simulated at K-net and DONET

Here, PGV and PGD values were obtained by applying the band-pass filter of frequency range $0.1-0.2 \mathrm{~Hz}$ to the observed and simulated waveforms. Data at distant stations located outside the simulation area and low quality data were removed from the plots. High-frequency signals were limited up to $0.2 \mathrm{~Hz}$ because of the effects of the numerical dispersion in the simulation results.

Good agreement is found between the observation and simulation for PGV and PGD values at most of the stations in Fig. 5. One of the noticeable features is that PGV and PGD at DONET stations are significantly large independent of their large hypocentral and epicentral distances. For example, PGV and PGD for Event 1 (Table 1) at K-net station MIE014 (see Fig. 1 for location) are $3.7 \times 10^{-4} \mathrm{~cm} / \mathrm{s}$ and $3.2 \times 10^{-4} \mathrm{~cm}$, respectively, while amplitudes at DONET station KMA01 are $1.5 \times 10^{-3} \mathrm{~cm} / \mathrm{s}$ and $1.6 \times 10^{-3} \mathrm{~cm}$, respectively, which are approximately several times larger than those at MIE014. Waveforms between these stations are also seen to be quite different as shown in Fig. 4. Waveforms at KMA01 show a much longer duration of strong motions, both in the observation
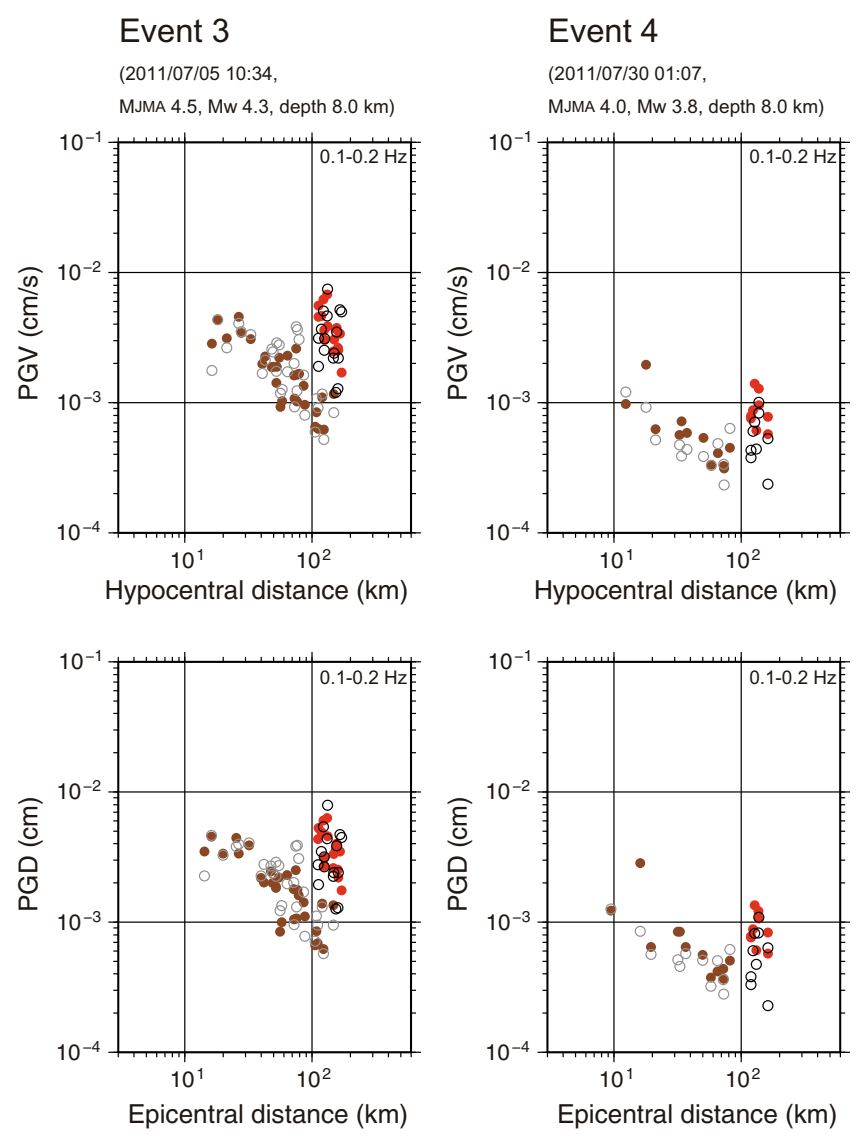

stations, respectively. Data at distant stations located outside the simulation area and low quality data were removed from this figure. It should be noted that observed PGV and PGD are significantly large at DONET stations independent of distances

and the simulation, compared to those at MIE014. These differences in amplitude and waveform may be caused by significant differences in the subsurface structures below the stations. Another noticeable feature found in our plots is the significant variation of PGV and PGD among the DONET stations (Fig. 6), indicating a trend that low levels are observed at stations near the trough axis such as stations KMC09 and high at other stations such as KMA01-04. In the "Discussion" section that follows, we discuss the relation of the variations of peak amplitudes to the subsurface structures between K-net and DONET stations and also among DONET stations.

\section{Discussion}

Cause of anomalously large seismic amplitudes

We have shown that PGV and PGD values for low-frequency components are large at DONET stations compared to those at $\mathrm{K}$-net stations, and the values among DONET stations are considerably different. In order to compare the spatial 


\section{Event 1}
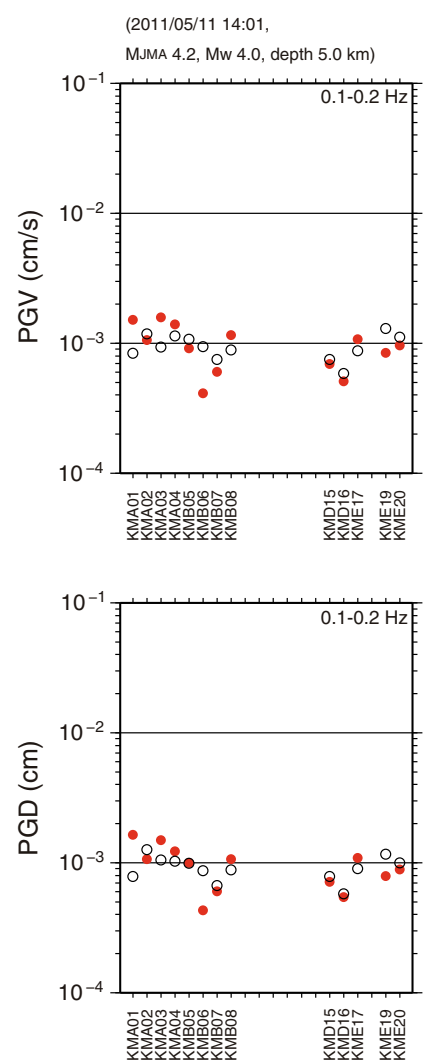

Event 2
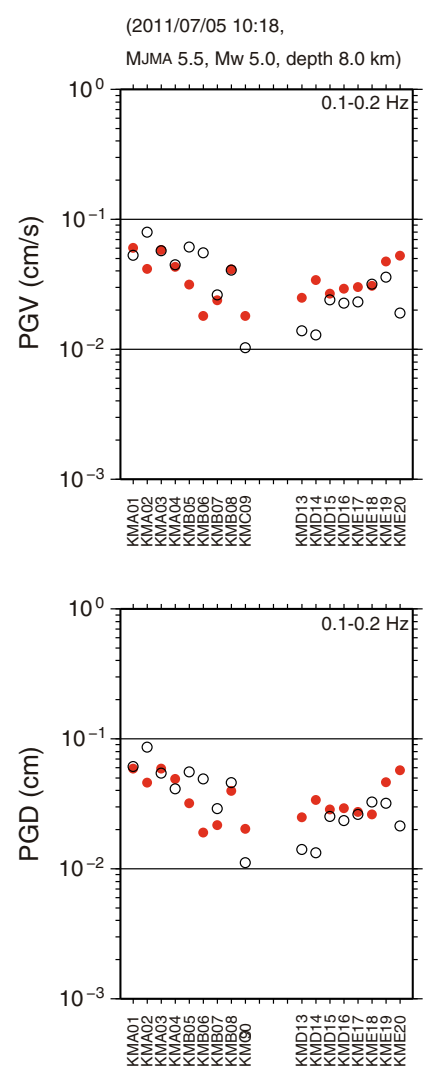

Fig. 6 Comparison of PGV and PGD for synthetic and observed waveforms in the frequency range $0.1-0.2 \mathrm{~Hz}$ at DONET stations. Solid red and open black circles indicate the observed and simulated amplitudes, respectively. Low quality data are removed in this figure.

distribution of seismic amplitudes between the land and ocean area, snapshots of vertical velocity components in seismic wave propagation are shown in Fig. 7. In the early stage (at 20 s in Fig. 7d), we can see trapped seismic energy consisting of body waves ( $P$ and $S$ waves) in the oceanic crust and the sediment layers. The body waves in the oceanic crust then enter the sediments (at 20 and $40 \mathrm{~s}$ ) and, as time progresses, energy which consists primarily of surface waves can be found in sediment layers and the seawater layer (at 80 and $160 \mathrm{~s}$ ). These imply that large amplification and elongation of seismic motions are expected around DONET stations. The energy within the sediment layers is relatively large off the coast, which is related to the presence of the thick sediment layers with very slow seismic velocities (Fig. 7b, c). On land, the seismic energy rapidly propagates through subsurface media and barely become trapped as time progresses. It is likely that this is the cause of simple waveforms with short durations of main phases at K-net stations as shown in Fig. 4.

The large amplifications seen in seafloor stations off the Kii peninsula have also been indicated in waveform simulation

Event 3
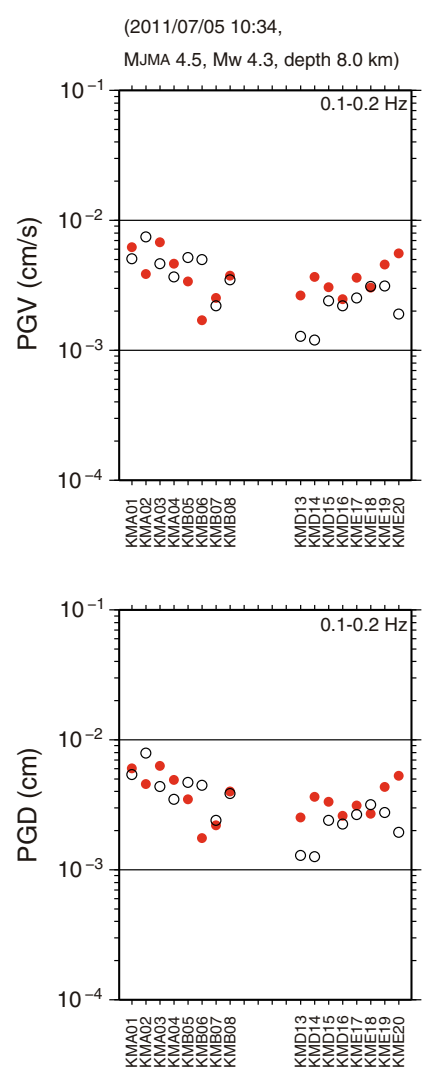

Event 4
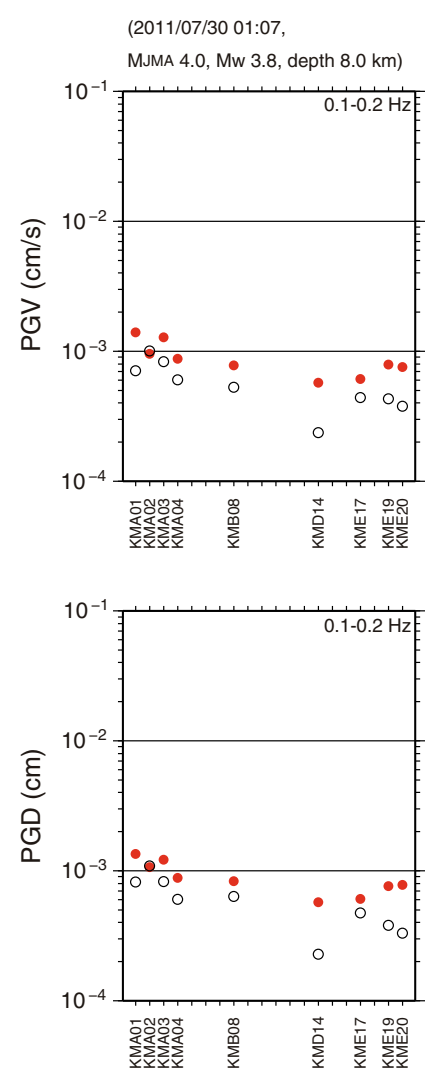

Note that stations KMC10-12 had not been installed before the events, and therefore no data are plotted. It should be noted that observed PGV and PGD are relatively low at stations such as KMC09 near the trough axis, while high at other stations such as KMA01-04

for landslide sources by Nakamura et al. (2014). Their study focused on signals with a frequency range of less than $0.1 \mathrm{~Hz}$. Despite the differences in the frequency components and source mechanisms used and those used in our study, their simulations show that seismic energy is trapped in sediment layers, which is similar to the findings of this study. Such a similarity could be related to the fact that the main seismic energies from the sources to the stations propagate in shallow regions in both studies. By a comparison of simulations using models with and without a seawater layer, their simulations also showed that at DONET stations the vertical component (primarily composed of Rayleigh waves) is amplified several times by the presence of a seawater layer. The waves for the model with a seawater layer are less dispersive, and simultaneously arrive at the stations, resulting in large amplitudes at DONET stations. From analyses of pop-up type ocean bottom observations for very-low-frequency events off the Kii peninsula, Sugioka et al. (2012) also showed that the seismic wave propagation in this ocean area is affected by the seawater layer and the sediment layers. Although the amplifications may 
(a) Structure model (Vp)

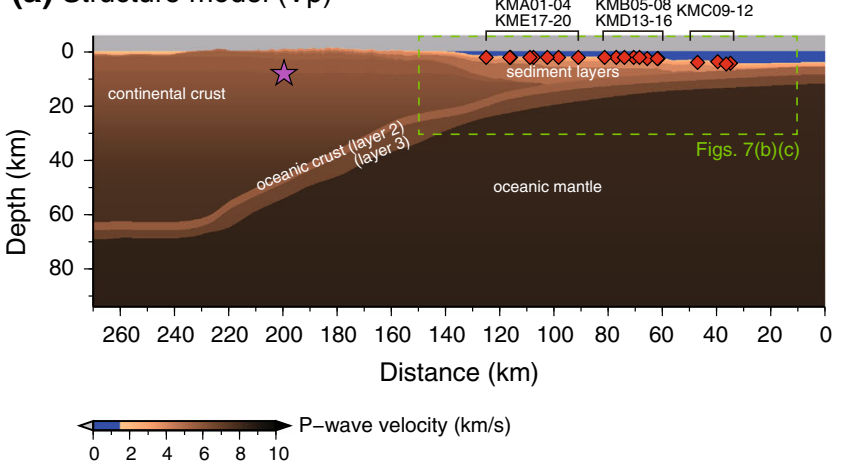

(b) Enlarged section of structure model (Vp)

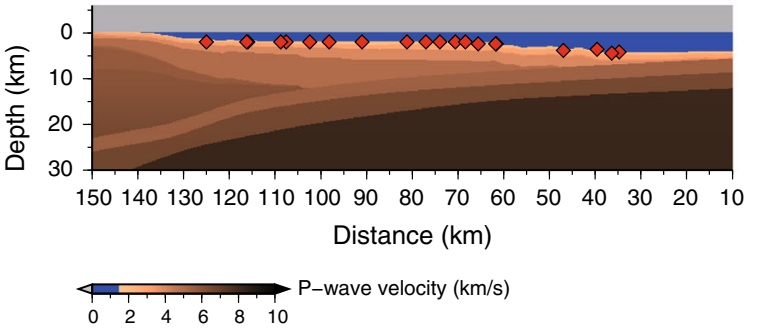

(c) Enlarged section of structure model (Vs)
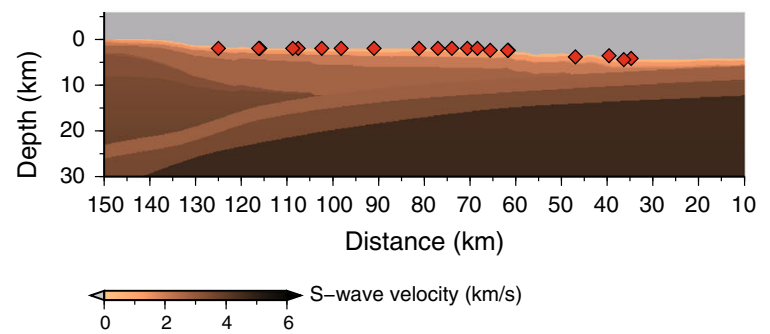

Fig. 7 a Structure model at the cross section in a southeastnorthwest direction (a dot line in Fig. 1) used in our simulation. b Enlarged cross section of the structure model for $P$-wave velocity $(V \mathrm{p})$ around DONET stations (red diamonds). c Enlarged cross section of the structure model for $S$-wave velocity ( $V \mathrm{~s})$ around DONET stations. d Snapshots of the vertical velocity component at

depend on the source depth, similar amplifications at suboceanic events around DONET stations would be expected because of not only the sediment layers but also a seawater layer. It is considered likely that such an amplification and also long coda of seismic motions are expected at seafloor observation stations on thick sediment layers in other deep ocean areas, too.

Effect of seismic amplifications on magnitude estimation

Displacement amplitudes at single stations can be used to make rapid estimations of magnitudes for EEW (e.g., Wu (d) Snapshot
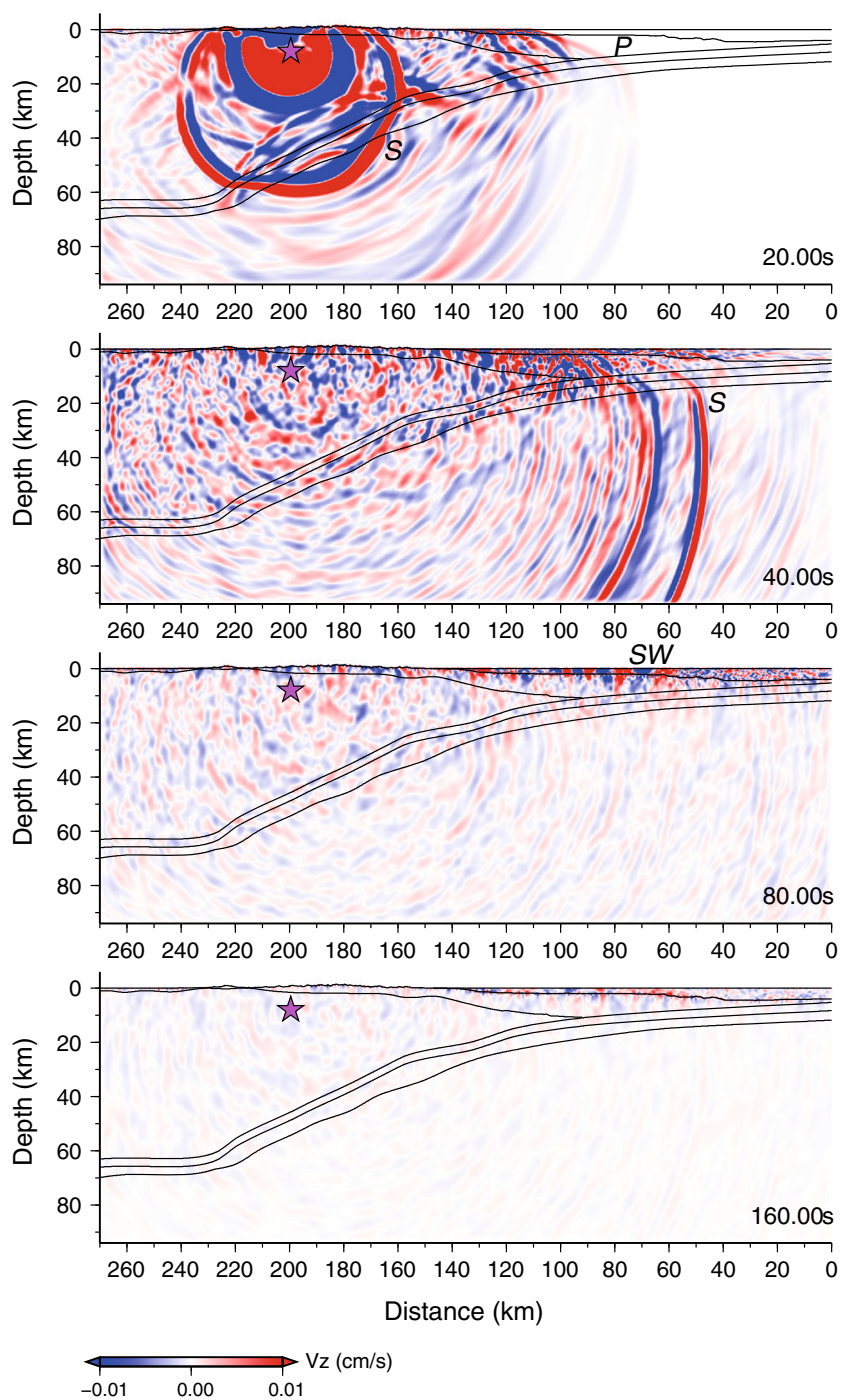

20, 40, 80, and $160 \mathrm{~s}$ for the event at 10:18 UTC on July 5, 2011 (Event 2 in Table 1). The purple star in each shot indicates the location of the hypocenter. Black lines indicate land and sea surfaces, seafloor, upper surfaces of oceanic crusts (layers 2 and 3), oceanic mantle, and seismic basements. $P, S$, and $S W$ denote $P$-wave, $S$-wave, and surface wave, respectively

et al. 2006). Estimated magnitudes are critical parameters in determining whether warnings should be issued or not, and also for evaluating strong motions in target areas using empirical equations.

In order to study the feasibility of DONET data for use in EEW, we estimated magnitudes using displacement amplitudes from single stations (at both K-net and DONET stations) in a frequency range of $0.1-10 \mathrm{~Hz}$, and compared them with the JMA catalogue magnitude. We used the empirical equation proposed by Tsuboi (1954), which relates the displacement amplitudes to the magnitudes as used in Fig. 3. In Fig. 8, we plot the difference between the magnitudes estimated from displacement data and those of 
Fig. 8 Comparison of magnitudes estimated from PGD at each station in the frequency range $0.1-10 \mathrm{~Hz}$ with the JMA catalogue magnitudes. Left and right panels are the histograms showing the difference and the estimated magnitudes against the catalogue values, respectively. Upper and lower panels show results for K-net and DONET data, respectively
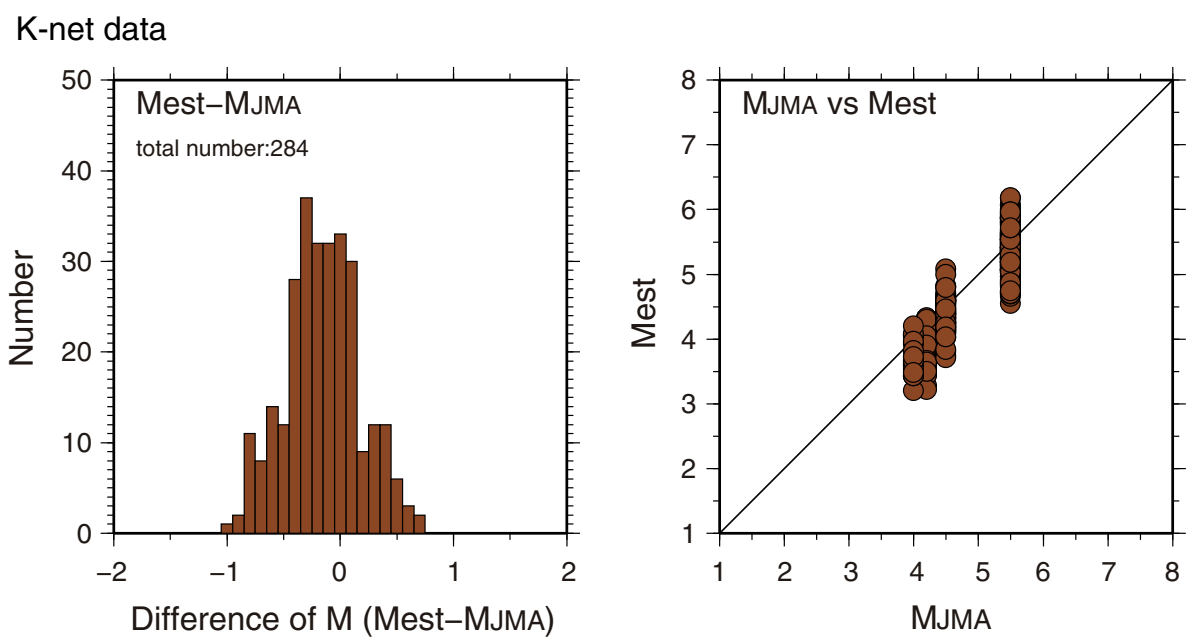

DONET data

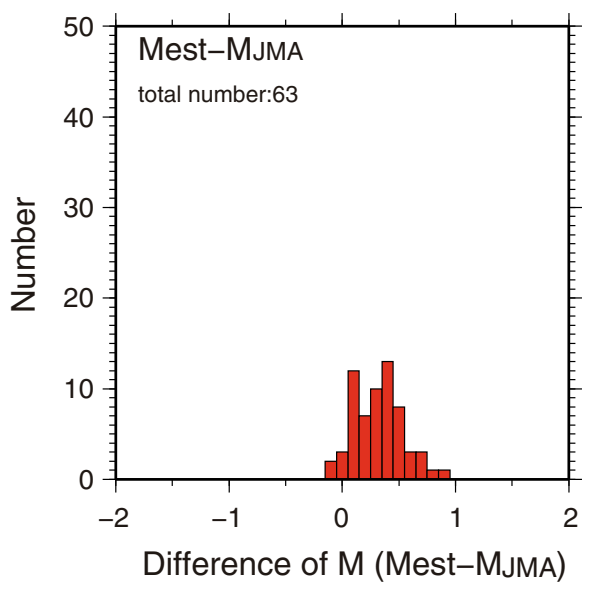

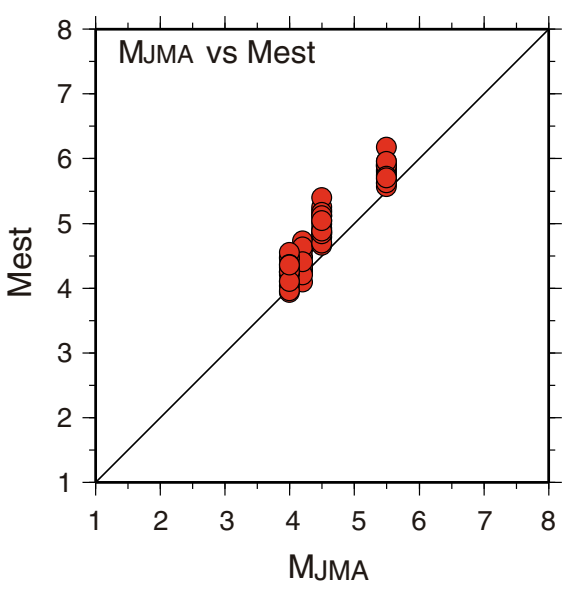

the JMA catalogue magnitudes. For K-net stations, the mean value of the difference, calculated by subtracting the latter magnitude from the former magnitude, at all stations for the four events, is $-0.15 \pm 0.33$. For DONET stations, the mean difference is $0.32 \pm 0.21$, and these magnitudes are systematically larger than those of the JMA catalogue. The two different values indicate that the magnitudes estimated from DONET data are larger than those estimated from K-net data by an approximate difference of 0.5 between DONET and K-net stations. This positive difference qualitatively corresponds to results of the large amplifications at DONET stations as shown in our simulation, which is attributed to subsurface structures in the ocean area. Analysis results of a $t$ test at a $5 \%$ significance level also show a significant difference between the mean value from K-net and DONET stations, which statistically allows us to reject a null hypothesis that the distribution of the K-net and DONET stations has a common mean value. Since the positive difference at DONET stations means that using displacement data can cause an overestimation of magnitudes, it is therefore considered necessary to incorporate amplitude corrections for DONET data into the estimation of magnitudes, so as to reduce such an overestimation and issue warnings precisely.

In Table 2, we list the difference for each DONET station between magnitudes estimated from displacement data and the JMA catalogue magnitudes, which may be used for evaluating corrections. Although we analyze only four events, Table 2 indicates that magnitude overestimation is relatively large at stations close to the land, compared to those near the trough axis, and that this trend is similar as shown in the "Comparison of peak amplitudes between observations and simulation results" section. Although the frequency band between these analyses is different, we consider that the obtained positive difference of magnitude at DONET stations and the distribution of the difference among DONET stations can be partially explained by seismic amplifications associated with the subsurface structures in the ocean area.

In this study, we showed results obtained only for moderate-sized inland crustal events. Since most of shallow events below DONET are of a magnitude less than 4 (Nakano et al. 2013) and low signal to noise ratio is 
Table 2 List of the difference in magnitudes recorded at each DONET station

\begin{tabular}{llllll}
\hline Station & Event 1 & Event 2 & Event 3 & Event 4 & Average \\
\hline KMA01 & 0.53 & 0.46 & 0.71 & 0.48 & 0.55 \\
KMA02 & 0.29 & 0.42 & 0.76 & 0.46 & 0.48 \\
KMA03 & 0.39 & 0.68 & 0.90 & 0.56 & 0.63 \\
KMA04 & 0.44 & 0.39 & 0.62 & 0.33 & 0.45 \\
KMB05 & 0.13 & 0.33 & 0.43 & 0.21 & 0.28 \\
KMB06 & 0.06 & 0.12 & 0.29 & 0.04 & 0.13 \\
KMB07 & 0.10 & 0.19 & 0.38 & - & 0.22 \\
KMB08 & 0.08 & 0.30 & 0.35 & 0.11 & 0.21 \\
KMC09 & - & 0.07 & 0.17 & - & 0.12 \\
KMC10 & - & - & - & - & - \\
KMC11 & - & - & - & - & - \\
KMC12 & - & - & - & - & - \\
KMD13 & - & 0.13 & 0.20 & -0.06 & 0.09 \\
KMD14 & 0.14 & 0.38 & 0.55 & 0.25 & 0.33 \\
KMD15 & 0.13 & 0.41 & 0.50 & 0.25 & 0.32 \\
KMD16 & -0.10 & 0.26 & 0.34 & -0.04 & 0.12 \\
KME17 & 0.15 & 0.39 & 0.67 & 0.26 & 0.37 \\
KME18 & - & 0.46 & 0.62 & 0.37 & 0.48 \\
KME19 & 0.01 & 0.23 & 0.39 & 0.11 & 0.19 \\
KME20 & 0.21 & 0.21 & 0.55 & 0.36 & 0.33 \\
\hline
\end{tabular}

expected for low-frequency components, we have not included near-field small events in the present study. Previous studies by Hayashimoto and Hoshiba (2012, unpublished results) and Hayashimoto and Hoshiba (2013) investigated the difference in magnitudes for events including distant ones with an epicentral distance of more than $200 \mathrm{~km}$ between those estimated from displacement data at seafloor stations and the JMA catalogue magnitudes. They showed an average magnitude overestimation of 0.6 , which is a very similar value to our results. However, a significant dependence of the magnitude difference on the event azimuth (back azimuth) is not found in their results. If little dependence on the event azimuth is also confirmed for near-field suboceanic events, the correction values presented by their results and our results would therefore be applicable to current magnitude estimation. It is considered, however, that further studies of seismic amplifications for such events are needed to verify the feasibilities of the corrections to seafloor observation data.

In this study, we focused on seismic amplifications in the frequency range $0.1-0.2 \mathrm{~Hz}$ in our simulation results. The upper limit of the frequency band used is due to the limitation of computational resources for waveform simulations and the resolution of structure models in this area. Further studies simulating high frequency components up to $10 \mathrm{~Hz}$ are required, since magnitudes are estimated using seismic signals including high-frequency components. In order to investigate amplifications in the high-frequency components, in future studies, we will analyze waveform data for high-frequency sources of seismic airgun surveys and also simulate seismic wavefields, using a large-scale computing system and employing shallow structures estimated from logging data around DONET stations.

\section{Conclusion}

Seismic wave amplifications were investigated in and around the Kii peninsula using observation data analyses and numerical simulations from land (K-net) and seafloor stations (DONET). Seismic amplitudes at DONET stations are found to be larger than those at K-net stations, independent of epicentral distances. We reproduced seismic waveforms using the finite-difference method, and investigated the cause of the amplifications. Our simulation results in the low frequency range $(0.1-0.2 \mathrm{~Hz})$ demonstrate that seismic waves are significantly amplified at DONET stations because of the effects of low-velocity sediment layers with a total thickness of up to $10 \mathrm{~km}$ below the stations. Simulation results also show that the spatial distribution of the amplifications among DONET stations correlates with the thickness of the sediment layers. Our results, based on observation data and simulations, indicate that the amplifications at DONET stations partially contribute to an overestimation of magnitude, if the same equations as those used for data observed at land stations are applied without any correction allowed for seismic amplification caused by ocean-specific structures. To reduce the overestimation, it is considered necessary to incorporate amplitude corrections into the estimations of magnitude. To obtain more accurate corrections, it is considered that further studies on seismic amplifications in high frequency components are also necessary by way of analyzing data for high-frequency sources and performing large-scale computations.

Acknowledgments Discussions with Yasushi Ishihara, Takayuki Miyoshi, and seismology members of the Japan Meteorological Agency (JMA) were extremely beneficial. Comments from two anonymous reviewers helped to improve the manuscript. Strong motion data recorded at K-net stations were obtained from the National Research Institute for Earth Science and Disaster Prevention (NIED). Topography data were provided by the Geospatial Information Authority of Japan (GSI). Bathymetric data were obtained from the Japan Oceanographic Data Center (JODC). The structural model of sediment layers was obtained from the Japan Seismic Hazard Information Station (J-SHIS). The JMA 2001 velocity model was provided by JMA. The FDM simulations were conducted using the ICE X system of the Japan Agency for Marine-Earth Science and Technology (JAMSTEC). The Generic Mapping Tools by Wessel and Smith (1998) were used for the figures. 
Open Access This article is distributed under the terms of the Creative Commons Attribution License which permits any use, distribution, and reproduction in any medium, provided the original author(s) and the source are credited.

\section{References}

Alford RM, Kelly KR, Boore DM (1974) Accuracy of finitedifference modeling of acoustic-wave equation. Geophysics 39:834-842

Araki E, Yokobiki T, Kawaguchi K, Kaneda Y (2013) Background seismic noise level in DONET seafloor cabled observation network. In: Proceedings of international symposium underwater technology 2013, Tokyo. doi:10.1109/UT.2013.6519858

Baba T, Hirata K, Hori T, Sakaguchi H (2006) Offshore geodetic data conducive to the estimation of the afterslip distribution following the 2003 Tokachi-oki earthquake. Earth Planet Sci Lett 241:281-292

Brocher TA (2005) Empirical relations between elastic wavespeeds and density in the earth's crust. Bull Seismol Soc Am 95:2081-2092

Drossaert FH, Giannopoulos A (2007) Complex frequency shifted convolution PML for FDTD modelling of elastic waves. Wave Motion 44:593-604

Espinosa-Aranda JM, Jiménez A, Ibarrola G, Alcantar F, Aguilar A, Inostroza M, Maldonado S (1995) Mexico City seismic alert system. Seismol Res Lett 66:42-53

Hayashimoto N, Hoshiba M (2013) Examination of travel time correction and magnitude correction of Tonankai ocean bottom seismographs for Earthquake Early Warning. Quart J Seismol 76:69-81 (in Japanese with English abstract)

Hoshiba M, Kamigaichi O, Saito M, Tsukada S, Hamada N (2008) Earthquake early warning starts nationwide in Japan. EOS Trans AGU 89:73-74

Iglesias A, Singh SK, Ordaz M, Santoyo MA, Pacheco J (2007) The seismic alert system for Mexico City: an evaluation of its performance and a strategy for its improvement. Bull Seismol Soc Am 97:1718-1729

Kamigaichi O, Saito M, Doi K, Matsumori T, Tsukada S, Takeda K, Shimoyama T, Nakamura K, Kiyomoto M, Watanabe Y (2009) Earthquake early warning in Japan: warning the general public and future prospects. Seismol Res Lett 80:717-726

Kanamori H, Brodsky E (2004) The physics of earthquakes. Rep Prog Phys 67:1429-1496

Kawaguchi K, Araki E, Kaneda Y (2011) Establishment of a method for real-time and long-term seafloor monitoring. J Adv Mar Sci Tech Soc 17:125-135 (in Japanese with English abstract)

Kikuchi M (2003) Realtime seismology. UniversityTokyo Press, Tokyo, p 222 (in Japanese)

Matsumoto H, Mikada H (2005) Fault geometry of the 2004 off the Kii peninsula earthquake inferred from offshore pressure waveforms. Earth Planets Space 57:161-166

Mikada H, Mitsuzawa K, Matsumoto H, Watanabe T, Morita S, Otsuka R, Sugioka H, Baba T, Araki E, Suyehiro K (2006) New discoveries in dynamics of an M8 earthquake-phenomena and their implications from the 2003 Tokachi-oki earthquake using a long term monitoring cabled observatory. Tectonophysics 426:95-105
Moczo P, Kristek J, Halada L (2000) 3D fourth-order staggered-grid finite-difference schemes: stability and grid dispersion. Bull Seismol Soc Am 90:587-603

Nakamura T, Takenaka H, Okamoto T, Kaneda Y (2012) FDM simulation of seismic-wave propagation for an aftershock of the 2009 Suruga Bay earthquake: effects of ocean-bottom topography and seawater layer. Bull Seismol Soc Am 102:2420-2435

Nakamura T, Takenaka H, Okamoto T, Kaneda Y (2014) Seismic wavefields in the deep seafloor area from a submarine landslide source. Pure Appl Geophys (in press). doi:10.1007/s00024-0130717-3

Nakanishi A, Takahashi N, Park JO, Miura S, Kodaira S, Kaneda Y, Hirata N, Iwasaki T, Nakamura M (2002) Crustal structure across the coseismic rupture zone of the 1944 Tonankai earthquake, the central Nankai Trough seismogenic zone. J Geophys Res 107. doi:10.1029/2001JB000424

Nakano M, Tonegawa T, Kaneda Y (2012) Orientations of DONET seismometers estimated from seismic waveforms. JAMSTEC Rep Res Dev 15:77-89

Nakano M, Nakamura T, Kamiya S, Ohori M, Kaneda Y (2013) Intensive seismic activity around the Nankai trough revealed by DONET ocean-floor seismic observations. Earth Planets Space 65:5-15

Romano F, Piatanesi A, Lorito S, Hirata K (2010) Slip distribution of the 2003 Tokachi-oki M-w 8.1 earthquake from joint inversion of tsunami waveforms and geodetic data. J Geophys Res 115 . doi:10.1029/2009JB006665

Si H, Midorikawa S (1999) New attenuation relations for peak ground acceleration and velocity considering effects of fault type and site condition. J Struct Construct Eng 523:63-70 (in Japanese with English abstract)

Sugioka H, Okamoto T, Nakamura T, Ishihara Y, Ito A, Obana K, Kinoshita M, Nakahigashi K, Shinohara M, Fukao Y (2012) Tsunamigenic potential of the shallow subduction plate boundary inferred from slow seismic slip. Nat Geosci 5:414-418

Takenaka H, Nakamura T, Okamoto T, Kaneda Y (2009) A unified approach implementing land and ocean-bottom topographies in the staggered-grid finite-difference method for seismic wave modeling. In: Proceedings of 9th SEGJ international symposium Sapporo. doi:10.1190/SEGJ092009-001.13

Tsuboi C (1954) Determination of the Gutenberg-Richtere's magnitude of earthquakes occurring in and near Japan. Zisin 2 ( $\mathrm{J}$ Seismol Soc Jpn) 7:185-193 (in Japanese with English abstract)

Ueno H, Hatakeyama S, Aketagawa T, Funasaki J, Hamada N (2002) Improvement of hypocenter determination procedures in the Japan Meteorological Agency. Quart J Seismol 65:123-134 (in Japanese with English abstract)

Watanabe T, Takahashi H, Ichiyanagi M, Okayama M, Takada M, Otsuka R, Hirata K, Morita S, Kasahara M, Mikada H (2006) Seismological monitoring on the 2003 Tokachi-oki earthquake, derived from off Kushiro permanent cabled OBSs and landbased observations. Tectonophysics 426:107-118

Wessel P, Smith WHF (1998) New, improved version of Generic Mapping Tools released. EOS Trans AGU 79:579

Wu YM, Teng TL (2002) A virtual subnetwork approach to earthquake early warning. Bull Seismol Soc Am 92:2008-2018

Wu YM, Yen HY, Zhao L, Huang BS, Liang WT (2006) Magnitude determination using initial $\mathrm{P}$ waves: a single-station approach. Geophys Res Lett 33:L05306. doi:10.1029/2005GL025395 